\title{
Patología y daños del lenguaje técnico.
}

\author{
V. Alegre ${ }^{1 *}$ \\ *Vicente Alegre Heitzmann: info@,cotca.com \\ ${ }^{1}$ COTCA, S.A., UPC, Barcelona, España
}

\begin{abstract}
RESUMEN
La importancia de utilizar bien el lenguaje es una tarea que viene de lejos, la palabra es una herramienta clave desde que los homínidos se convierten en seres sociables. Se presenta aquí algún ejemplo histórico y varios actuales para incidir en la necesidad de plantear la mejora continua en la comunicación, que el lenguaje técnico escrito gane en claridad y precisión, y sea capaz de empatizar con el lenguaje social, político, periodístico, forense, convirtiéndose en una búsqueda común de la verdad. En el futuro se ha de ser capaz de acercarse al lenguaje poético que las estructuras nos enseñan comportándose y agrietándose con el lenguaje técnico asociado al principio de la mínima energía con que nos hablan.
\end{abstract}

Palabras clave: lenguaje, técnico, energía, daños, poesía. 


\begin{abstract}
The importance of using language properly is a task that comes from far ago, the Word is a key tool since hominids become sociable beings. Some historical and several current examples are presented here to influence the to propose continuous improvement in communication, so that written technical language gains clarity and precision, and it can empathize with social, political, journalistic, forensic language, becoming a jointly search for the truth. In the future, it will be necessary to be able to approach the poetic language that structures teach us, behaving and cracking with the technical language associated with the principle of the minimum energy with which they speak with us.
\end{abstract}

Key words: language, technical, energy, damage, poetry.

\title{
RESUMO
}

A importância de usar bem a linguagem é uma tarefa que vem de longe, a palavra é uma ferramenta fundamental, já que os hominídeos se tornam seres sociais. Alguns exemplos históricos e diversos atuais são apresentados aqui para influenciar a necessidade de propor melhoria contínua na comunicação, que a linguagem técnica escrita ganhe clareza e precisão, e seja capaz de empatizar com a linguagem social, política, jornalística, forense, tornando-se uma busca comum pela verdade. No futuro, será necessário saber abordar a linguagem poética que as estruturas nos ensinam, comportando-se e rachando com a linguagem técnica associada ao princípio da energia mínima com que nos falam.

Palavras-chave: linguagem, técnica, energia, dano, poesia.

\section{INTRODUCCIÓN}


Las estructuras y los subsistemas ligados a ellas se comunican con el entorno y se puede hablar con ellas, porque dicen dónde les duele, utilizando un lenguaje que gasta la mínima energía para expresarse. Es un hablar lleno de matices que hemos de ser capaces de descifrar y traducir a un lenguaje "técnico" que refleje correctamente el mensaje de la estructura y su entorno.

El lenguaje es una herramienta clave desde los tiempos bíblicos "En el principio era la palabra..." (1). No obstante, la palabra está siendo denostada por muchos que viven tergiversando el lenguaje o utilizándolo sin la necesaria precisión técnica, difícil, o incluso, sin la debida ética.

En este artículo se reivindica el correcto uso de la palabra, uso que muchos técnicos han tratado de desarrollar. Es el caso de uno de los primeros promotores e impulsores de estos "Congresos de control de calidad y patología de la construcción” CONPAT, el profesor y Doctor Ingeniero de Caminos, Álvaro García Meseguer, que en un memorable artículo en 1985 (2) ya señalaba que "la frontera entre las ciencias aplicadas y las ciencias sociales ha perdido ya su sentido. En la base de este mundo unitario se sitúa el lenguaje".

Aunque la transversalidad del conocimiento nos permita creer que todos sabemos de todo, hay que tener la humildad suficiente para reconocer cuán lejos estamos de expresarnos correctamente, de conocer en profundidad el lenguaje y en concreto el de las patologías constructivas.

Estadísticamente, sabemos que un $75 \%$ de las causas de los daños son errores humanos y de ellos el factor que más influye es el de las deficiencias en la comunicación con porcentajes de hasta el $82,4 \%$ (3) de ese $75 \%$.

La comunicación es "la acción y efecto de hacer saber algo a alguien" y es el proceso por el cual se envían y reciben mensajes. Según Shoet y Frydman (4) un 52\% de toda la comunicación utilizada permanece registrada por tener un formato escrito. Al lenguaje escrito que contribuye a explicar las causas de los daños se refiere este artículo.

\section{LA IMPORTANCIA DEL LENGUAJE}

El lenguaje técnico es el que trata de interpretar el comportamiento de las estructuras siguiendo también el principio de la mínima energía, y creando conceptos y condensando palabras que nos ayuden a describir con criterio técnico los estados límites últimos y de servicio de las estructuras para valorar el riesgo de disfunciones.

Empezaré reconociendo mis limitaciones con un ejemplo. He hablado al comenzar de la importancia ya bíblica de la "palabra" que traducida del griego "logos" podría haber sido "el verbo" que tiene unas connotaciones más trascendentes, que son objeto de un lenguaje poético que no alcanzo, y que se expresa en el siguiente poema de Juan Ramón Jiménez (5) que busca la esencia de la palabra, su "nombre exacto":

"iIntelijencia, dame

el nombre exacto de las cosas!

...Que mi palabra sea

la cosa misma,

creada por mi alma nuevamente.

Que por mí vayan todos

los que no las conocen, a las cosas;

que por mí vayan todos

los que ya las olvidan, a las cosas;

que por mí vayan todos

los mismos que las aman, a las cosas...

iIntelijencia, dame

el nombre exacto, y tuyo,

y suyo, y mío, de las cosas!" 


\subsection{El lenguaje técnico en la historia.}

Desde el punto de vista técnico-práctico algunos ejemplos documentales de gestión de daños se citan resumidamente y solo a modo de ilustración a continuación, con la terminología y la idiosincrasia de cada época:

\subsubsection{Siglo XVII (a. d. C.)}

El código de Hammurabi (1692 a.C. - Figura 1) gestiona los daños, con daños cruelmente proporcionales. Aparece el lenguaje forense de la justicia, aunque con penas, como se verá, muy distintas a las actuales (6).

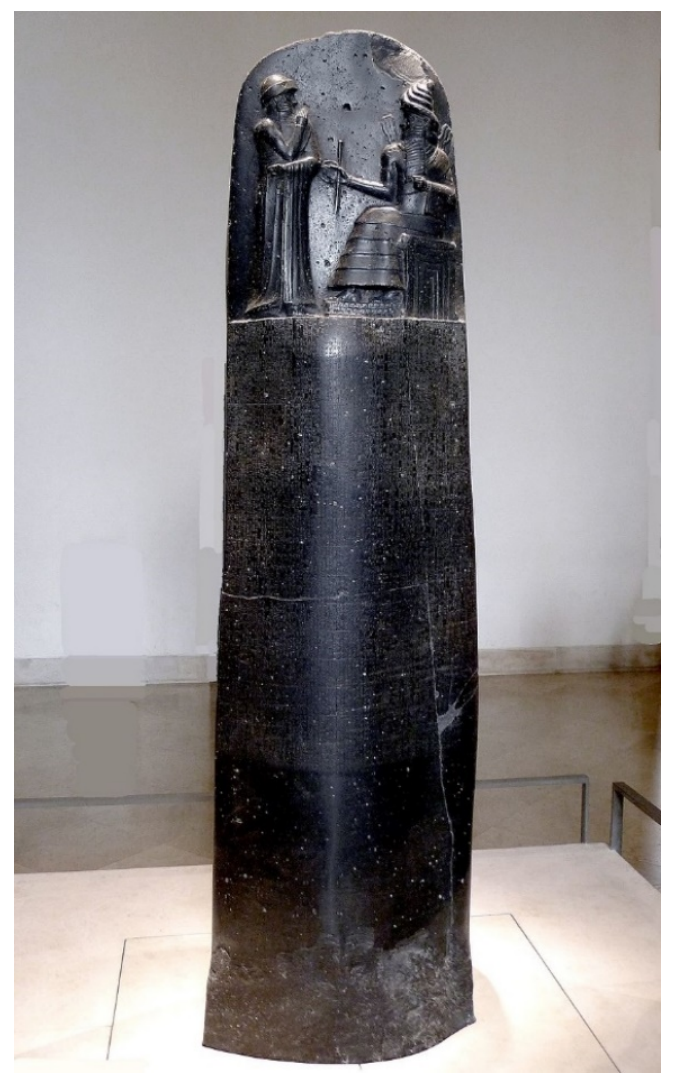

Figura 1. Código de Hammurabi.

"Si un constructor ha edificado una casa para un patricio, pero no ha hecho la obra sólida, de modo que la casa que ha construido se ha caído y ha causado la muerte de su propietario, el constructor será muerto.

Si el constructor ha causado la muerte del hijo del propietario de la casa, su hijo será muerto. Si se ha causado la muerte del esclavo del propietario de la casa, dará al propietario un esclavo a cambio."

\subsubsection{Siglo I}

Volvamos a la palabra poética. Las grietas son siempre un lenguaje positivo porque indican el camino técnico a seguir. Las grietas transmiten un "lenguaje", en el siguiente caso que citaré se trata de un lenguaje de amistad porque el daño estaba estabilizado.

Véase el efecto de la grieta en el muro de la fábula de Píramo y Tisbe (7), tal como la narra Ovidio en el siglo 1; leamos a Ovidio: 
"Píramo y Tisbe, él el más bello de los jóvenes, ella la más excelsa de las muchachas que en Oriente habia, vivían en casas contiguas, alli donde dicen que Semíramis ciñó con murallas de ladrillo su ilustre ciudad. La vecindad hizo que se conocieran y que su amistad diera los primeros pasos, el tiempo hizo que creciera su amor. Y se habrian unido en legítimo matrimonio si sus padres no se lo hubiesen prohibido; pero no pudieron prohibir que ambos ardieran cautivos por la misma pasión. Nadie está al corriente de su amor, se comunican con gestos y señas, y el fuego, encubierto, más arde cuanto más se le cubre.

En la pared que separaba las dos casas se abría una estrecha rendija que se había formado tiempo atrás, cuando el muro había sido construido. Durante largos siglos nadie habia notado ese defecto: fuisteis vosotros, enamorados, los primeros en verla (¿qué se le escapa al amor?), y en hacer de ella un camino para vuestras voces; a través de ella solian viajar seguras, en murmullos casi inaudibles, las tiernas palabras que os decíais. Muchas veces, cuando se hallaban uno a cada lado, Tisbe aquí, Píramo allí, y ambos habian percibido la respiración de sus bocas, decian: “¿Por qué te interpones en nuestro amor, pared cruel? ¿Qué bueno sería que nos permitieras unir por entero nuestros cuerpos o, si eso es pedir demasiado, que nos dejaras espacio para un beso! Pero no somos desagradecidos: sabemos que a ti te debemos que nuestras palabras puedan llegar a oídos amigos."

Los amantes no solo hablan a través del muro y de sus grietas, sino que se dirigen al muro mismo, agradeciéndole su complicidad. La poesía de Ovidio humaniza, como se puede ver, el muro y el daño.

\subsubsection{Siglo XVIII}

Ya en la edad contemporánea se pierde la poesía, al menos en el siguiente caso. El primer hecho perfectamente documentado en España de la gestión de un daño, en el que intervienen todos los agentes, es el problema que podríamos titular como "La viga de Ohanes" que, además de reflejar la idiosincrasia de la época, nos acerca a los casos actuales que siguen en ocasiones pautas parecidas o casi idénticas.

*Ohanes de las Alpujarras (1734-1740 d.C.). Ver a continuación el texto adjunto (8) en el que, de forma resumida, el maestro en 1934 se queja al alcalde de tener una viga de la cubierta de la escuela rota, el alcalde manda sin prisas a los peritos, éstos informan de que "la viga amenaza caer pero nunca aplastar" y, posteriormente, en 1740, se cae la viga y mata al maestro y a los 14 alumnos que había en el aula, y queda demostrado según el cronista de la época que fue un accidente fortuito. -La educación del maestro:

"Tengo el honor de poner en su conocimiento la inquietud que me produce ver la viga que media la clase que regento pues está partida por medio, y ha formado una especie de embudo que recoge las aguas de las lluvias y las deja caer a chorro tieso sobre mi mesa de trabajo... espero de su amabilidad ponga coto a esto si no quiere que ocurra alguna desgracia con los niños y su maestro". Este su muy seguro servidor. Dios guarde a usted muchos años. Ohanes. Firmado y rubricado. 1734.

-La prepotencia del alcalde (administración), que contesta al año siguiente (1935), diciendo:

"Recibo con gran extrañeza el oficio que ha tenido a bien dirigirme y me apresuro a contestarle, es cosa rara que los agentes de mi autoridad no me hayan dicho nada de eso referente a la viga y, es más, pongo en duda que se encuentre en esas condiciones pues según me informa el tio Sarmiento no hará 60 años que se puso...”.

Tras otro cruce de cartas en octubre de 1735, después de reñirle por pesado le dice: "No obstante, nombraré una comisión que me informe sobre el asunto de la viga".

-La terminología y el lenguaje de los peritos (peritos de parte) un año después (mayo 1736):

"La dicha viga no se ha caído solo se ha bajado cosa de 10 o 12 deos, amenazando solo caer pero nunca juntarse con el suelo aplastando a los que coja dentro...” y tratan de explicarlo mejor "pero 
como quiera que la madera es un cuerpo astilloso tiene que crujir antes de pegar el golpazo, dando tiempo a que se salven...".

-El cronista de la villa, seis años después (diciembre 1740):

"El día 14 de octubre del año de Nuestro Señor Jesucristo 1740, siendo alcalde de esta villa Don Bartolomé Zancajo y Zancajo y siendo las doce de su mañana se hundió el techo de la escuela de esta localidad, pereciendo en el siniestro el señor maestro de primeras lecturas D. Zenón Garrido Martín y los 14 niños que en aquellos momentos daban su clase.

Abierto el oportuno expediente se ha podido comprobar que, por parte de la autoridad competente se tomaron todas las medidas... ver informe del buen estado del local de 1736... quedando plenamente demostrado que únicamente un accidente fortuito fue el responsable del hundimiento". En este documento ya se dibuja el perfil de los intervinientes y sus intereses, y podríamos abrir la discusión de quiénes son los responsables del desaguisado y en qué porcentaje.

Lo que no se le puede negar al pasado es la importancia y contundencia de la palabra, sin cuyo desarrollo no existiría el mundo que conocemos. La "palabra de honor" y un choque de manos, tenía un valor eterno, incuestionable y permitía cerrar tratos y negocios de forma indeleble, incontestable. En la actualidad un contrato de un tema técnico con la administración requiere tiempo (mucho), abogados y futuros desencuentros. Contra eso, los técnicos luchamos creando obras de "urgencia" e incluso de "emergencia" para poder dar respuesta técnica a la gestión de daños, a pesar de las trabas administrativas, políticas y sociales.

\subsection{El lenguaje técnico en la actualidad.}

Las grandes catástrofes inducen al avance de las tecnologías; también inciden en el lenguaje. Por ejemplo, la rotura en 1802 de la presa de Puentes de Lorca fue el detonante de la apertura por Agustín de Betancourt en España de la Escuela de Caminos, que fue, ha sido y será el fundamento e impulso del lenguaje técnico. De la misma forma, para los que ahora empiezan en los estudios de daños es importante conocer el lenguaje técnico y ampliar el lingüístico y las herramientas que ambos ofrecen para conectar con la sociedad. A ellos van dedicadas estas líneas que solo pretenden, a través de ejemplos poco estructurados, seguir despertando la inquietud por la mejora continua de un tema que es tan inabarcable como esencial.

En esa línea, en el 2014 se presentó el Diccionario Español de Ingeniería que cuenta con más de 50.000 entradas y 1500 glosarios. En su elaboración trabajaron durante más de una década 100 especialistas. En un artículo reciente de la Revista de Obras Públicas (9) se nos invita a enviar palabras que no figuran en él.

El lenguaje actual no siempre aprecia la sinceridad, puede ser sibilino, es ruidoso ("el ruido hace nacer en el ignorante la idea de la fuerza" como se observa, volviendo a la transversalidad, en muchos discursos políticos), dista de ser cercano y amable, consensuado y, últimamente, contagiado por el ambiente político y social, no teme "propagar el bulo y la mentira".

El lenguaje técnico se incorpora a todos lo que intervienen en el proceso constructivo: arquitectos, ingenieros, técnicos, periodistas, peritos, abogados, políticos y la sociedad en general, todos con sus "tics" y sus limitaciones de conocimiento técnico y/o lingüístico.

Y en esto cabe siempre recordar la sentencia de Eduardo Torroja:

"Es importante que el ingeniero de caminos aprenda idiomas, por lo menos uno, el español".

\subsubsection{Palabras que triunfan inopinadamente, sin estar bien definidas o aplicadas.}

Veamos a continuación algunos ejemplos de términos que han triunfado, aunque a veces inmerecidamente:

\section{*Riesgo cero}


Se suele afirmar: "La solución que se utiliza ha de tener riesgo cero", cuando todos sabemos que el riesgo cero no existe, será $10^{-6}$, pero no cero.

\section{*Aluminosis}

El cemento aluminoso tiene muchas aplicaciones y no precisamente negativas, pero los edificios tienen "aluminosis", sin saber si es culpa de la curva de endurecimiento del cemento, de la transformación de los aluminatos, de la hidrólisis alcalina, o de la carbonatación del hormigón, o de todas esas causas o de parte de ellas. La realidad es que hay cientos de miles de metros cuadrados de forjados de viguetas fabricadas con cemento aluminoso sin problemas tras más de 50 años de vida útil.

\section{*Muro verde}

Otras palabras consiguen desplazar con carácter publicitario su verdadero rol estructural: por ejemplo "muro verde". Pero lo cierto es que el elemento de contención (muro) no es verde (Figura 2). Se sugiere que las plantas que crecerán en el "talud" colaborarán a contener la superficie de las tierras (Figura 3). El muro llamado verde es en realidad un talud reforzado con armaduras en cuya superficie crecen las plantas que al enraizarse refuerzan el perímetro. Reforzar antes de empezar puede parecer peyorativo, lo que no ayuda a su promoción y venta.

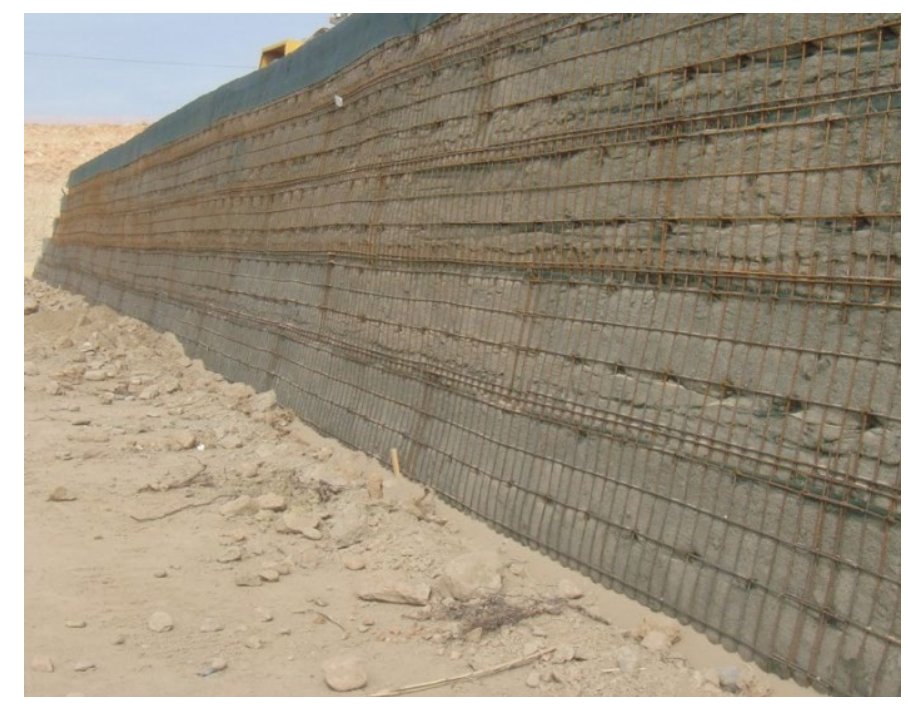

Figura 2. "Muro verde" recién ejecutado.

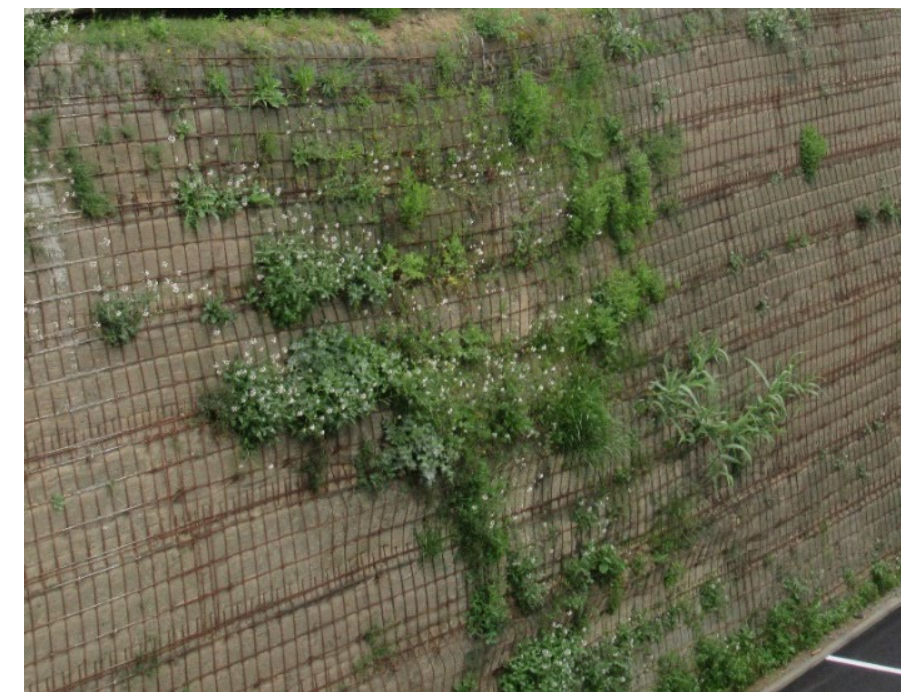

Figura 3. "Muro verde" tras el paso de 5 años. 


\section{*Forjado unidireccional}

El forjado unidireccional, siempre trabaja en las dos direcciones por el efecto placa en la dirección perpendicular, que permite la colaboración de las vigas adyacentes. El término "unidireccional" se entiende porque el forjado tiene el elemento resistente principal en una sola dirección, mientras que el bidireccional tiene elementos principales resistentes en las dos direcciones. Pero si, por ejemplo, quieres profundizar en el comportamiento deformacional, no puedes ceñirte a considerar una sola dirección.

*Pintura anti...

- Pintura anticarbonatación

En realidad, cualquier pintura lo es, porque frena como revestimiento activo el paso del $\mathrm{CO}_{2}$ del aire.

- Pintura antihumedad

Si tengo problemas de humedad, nada mejor que una "pintura antihumedad", aunque la causa no la arreglo y no servirá para nada, ni siquiera a corto plazo. Eso sí, los primeros días parecerá que está arreglado, mientras no se despierte la causa.

- Pintura ignífuga

La pintura resistente al fuego lo es, pero solo en unas condiciones determinadas de adherencia, espesor, compatibilidad y tiempo (para una resistencia al fuego de $\mathrm{X}$ minutos).

\section{*Plazas duras}

Nombre dado en los años 80 a las plazas pavimentadas, que subrayaba algo que ahora criticamos porque queremos volver "al verde", a la tierra.

\section{*Plaza verde}

Un "puente urbano de carretera", lenguaje ingenieril, difícilmente será una "plaza verde", lenguaje arquitectónico. Por mucho que se pongan bancos, muros vegetales (o sea, plantas trepando por una estructura metálica) y árboles, pasan coches y hay que poner barandillas que soporten una energía de impacto y cumplir la IAP-11 (instrucciones de puentes) (Figura 4).

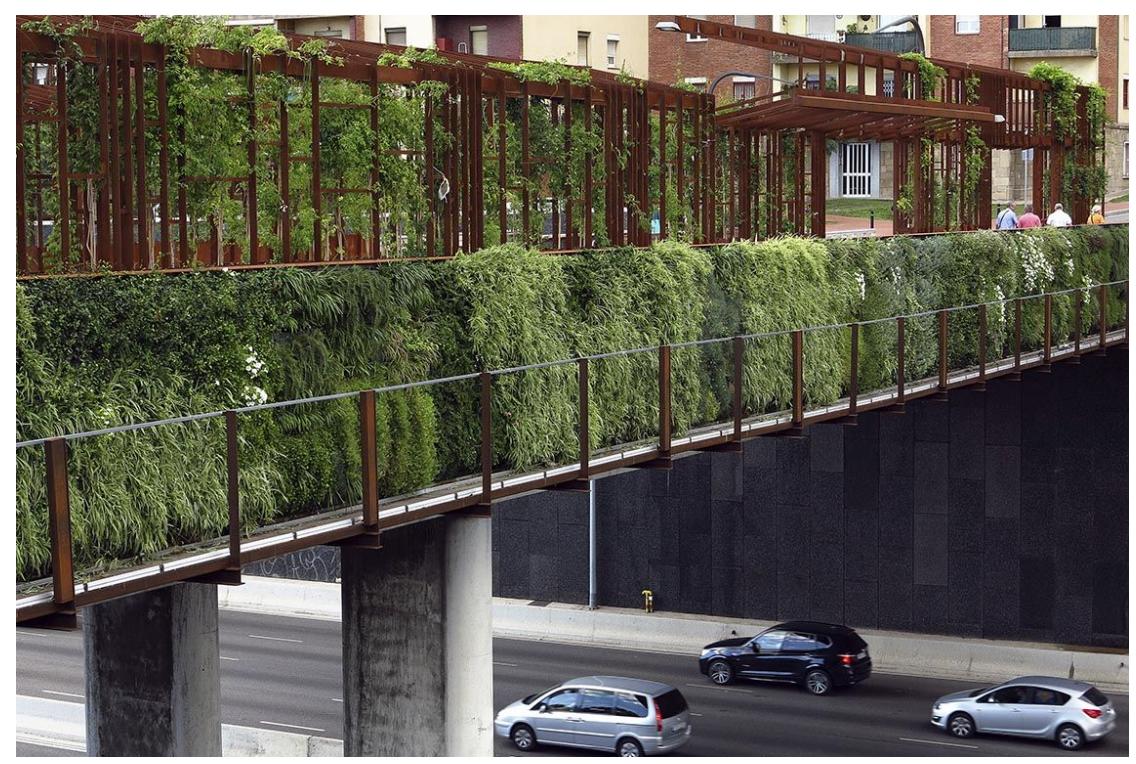

Figura 4. Ejemplo de "plaza verde" o "puente urbano".

\section{* Cargas conservativas}

Aquí debería utilizarse el lenguaje técnico común: "acciones o cargas permanentes, cargas variables, concargas y sobrecargas". Sin embargo, en ocasiones se busca un lenguaje que haga intuir al no técnico conceptos no normados técnicamente. Con ello inducen a la confusión, al no estar incluido ese concepto en el vocabulario de la normativa. 


\section{*El edificio es sólido}

En cierta ocasión para admitir el uso de un edificio que tras un percance se había arreglado, la administración exigía que se firmara que "el edificio es sólido"; una vez escrito y firmado por el técnico responsable, éste comentó irónicamente: "lo firmo porque ni es líquido, ni es gaseoso".

\section{*Características técnicas en las fichas}

Como su denominación indica, estas fichas deberían caracterizar técnicamente las propiedades del producto. Sin embargo, parapetados en que son productos con patentes, es habitual ver que con tal de vender subrayan con adjetivos calificativos, términos que se acercan a mentiras técnicas. Las fichas técnicas no deben decir, por ejemplo, "excelente adherencia" o "buena adherencia", sino que la "adherencia será superior a X de acuerdo con la norma Y".

De forma general, cuando controlo la calidad tengo que saber qué concepto o propiedad controlo. Por ejemplo, propiedad: "la consistencia"; con qué norma: la UNE EN 12350-2 (2006) y cuál es el criterio de aceptación y rechazo: Si he pedido consistencia blanda será entre 6 y $9 \mathrm{~cm}$ con una tolerancia de $\pm \mathbf{1 c m}$ (EHE-08). Este es el concepto de control de calidad.

Por esta razón, como técnicos no es admisible quedarnos solo en los adjetivos:

Los adjetivos comúnmente utilizados que deberíamos definir con propiedad son interminables: "fácil puesta en obra", "elevada resistencia a la difusión", "ecológico", "sumamente elástico", "gran resistencia", "especialmente indicado", "atenúa el ruido", etc.

Las fichas deben incorporar el lenguaje técnico:

- "Importante efecto barrera frente al agua". El efecto barrera se puede medir, por ejemplo, con el concepto de permeabilidad definida en la norma UNE-EN-12390-8, en que se establece como criterio de aceptación un valor medio y otro máximo.

Del mismo modo, es frecuente leer lo siguiente: "Adhiere perfectamente sin imprimación sobre la mayoría de los materiales de la construcción". Esto tendría cierto sentido siempre que la adherencia química y mecánica hubieran sido garantizadas previamente; la primera porque se aplica en el momento idóneo, dentro de su tiempo abierto, y la segunda porque al no imprimar he abierto el poro del material con algún tratamiento previo y siguiendo el protocolo del anejo 2 de la ICRI 97.

- Presenta un acabado "listo para pintar". Técnicamente hay que saber si pide planeidad, rugosidad, grado de humedad, limpieza... y todo ello siempre de acuerdo con una norma y un criterio de aceptación o rechazo.

\section{*Hormigón sin retracción}

A pesar de la denominación, la realidad es que no existe hormigón sin retracción, porque las reacciones de hidratación del hormigón llevan consigo la retracción del mismo, que es el acortamiento que sufre el hormigón endurecido cuando está expuesto al aire con humedad no saturada.

\section{*Hormigón de retracción compensada}

Aquí empezamos a acercarnos a la realidad, ya que, por ejemplo, colocamos aditivos con cementos expansivos que contrarrestan la retracción. Sin embargo, aquí también habría que ver a qué edades se compensan, si tienen distintas curvas de endurecimiento y hasta dónde se equilibran.

\section{*Mortero elástico}

¿A qué elasticidad se refiere? Todos tienen un módulo de elasticidad, ¿qué valor tiene?, ¿de acuerdo con qué norma?

\section{*El soporte ha de estar seco}

A veces la propia ficha te dice implícitamente que no apliques el producto: "el soporte ha de estar seco". Y, en realidad, no existe ningún material de obra seco, o sea sin agua, ya que cómo mínimo contiene la humedad de equilibrio que se establece con la humedad relativa y temperatura de su entorno. Si admite algo de humedad, se puede mejorar diciendo: "la humedad de la base será inferior al 6\%, y como eso suele ser también difícil, se puede decir mejor técnicamente (si es 
verdad): "para su aplicación será necesario que estemos tres puntos por encima de la temperatura de rocío para evitar que se produzcan condensaciones" antes de aplicar el producto.

En definitiva, hay siempre cosas más difíciles de controlar, pero si la norma (o el protocolo, cuando no hay norma) están establecidos se pueden controlar, es el caso del color del hormigón, ya que los colores tienen unas longitudes de onda definidas según un RAL con sus horquillas de valores. Otro ejemplo, menos técnico: Se puede controlar la calidad "estética" de un proyecto porque lo mide un jurado de especialistas con un protocolo previo establecido. Es decir, propiedad a controlar: la "estética"; norma: el criterio del jurado con su protocolo; criterio: el mejor puntuado de los presentados.

\section{*Los "titulares periodísticos"}

Sobre este tema, la casuística es muy extensa, y todos los días los periódicos nos sorprenden con nuevos textos fallidos.

Ejemplos periodísticos:

- Subtitular de "El Periódico" (Figura 5): "el centro fue construido hace 14 años en una zona de aguas subterráneas, por lo que podría ceder en cualquier momento bajo el peso del millar de alumnos que asisten a clase"'. Lo que había ocurrido tenía poco que ver con lo afirmado. Se trataba de un tramo de un forjado sanitario (suelo de planta baja), cerámico de $7 \mathrm{~m}$ de luz, que había colapsado por oxidación de armaduras. Eso sí, el terreno estaba en el delta del río Llobregat que tiene en esa zona el nivel freático a un metro de profundidad, lo que produjo una también "profunda" y errónea inquietud periodística.

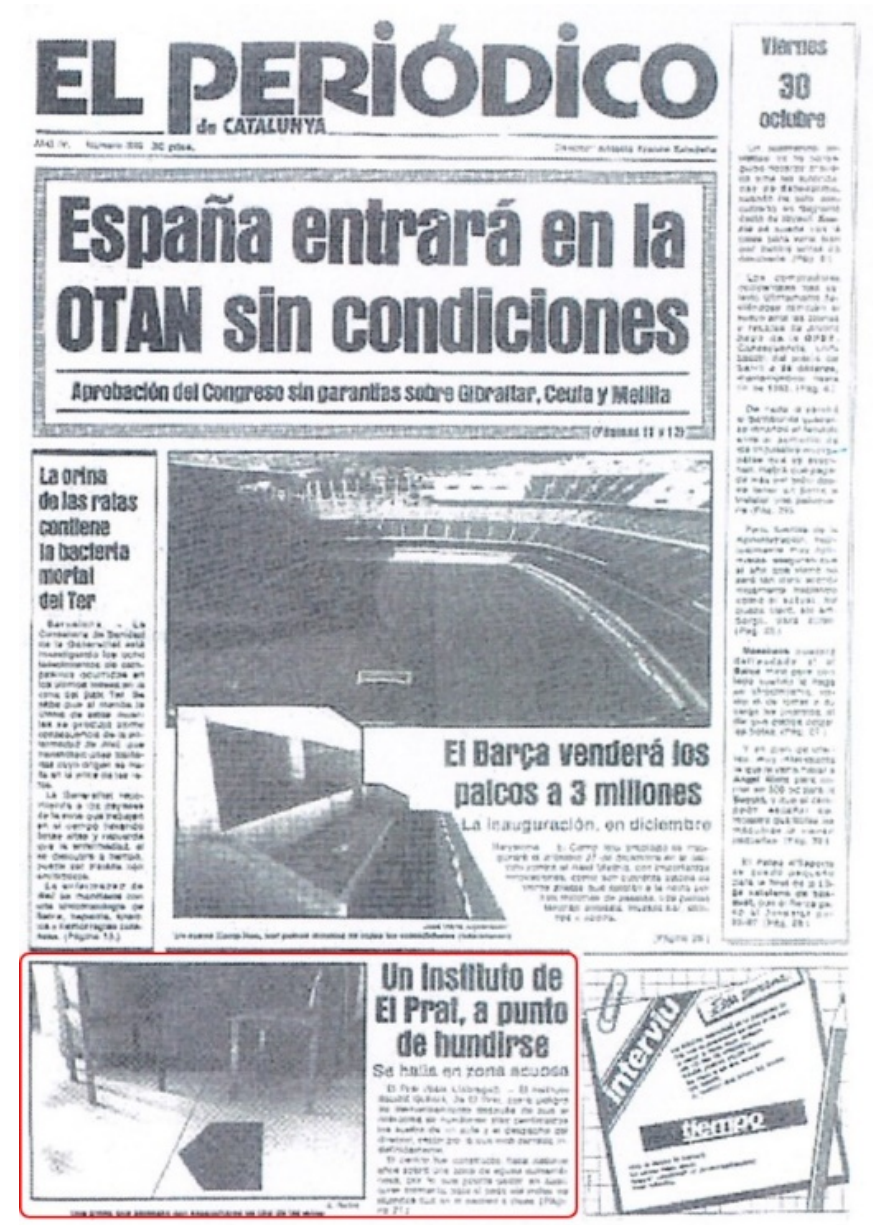

Figura 5. Portada de "El Periódico" con dicho titular. 
- Otro titular “demoledor": "Una tuneladora hunde una estación de metro". Efectivamente, la instrumentación marcaba un descenso de un centímetro en el punto más desfavorable tras el paso de la tuneladora por debajo de la estación. La subsidencia máxima de un centímetro cuando vaciamos el terreno para hacer el túnel, si la estamos controlando (midiendo), puede servir de aviso en el plan de contingencias, pero no de alerta o alarma, no la hemos "hundido".

*Ejemplos reales de empresas de derribo, que encierran en su nombre su filosofía:

"El fiera. Excavaciones y derribos". Véase cómo el nombre indica la agresividad empresarial (Figura 6).

"BCN Demolicions Pau", que con tanta "paz" ya no existen en la actualidad, han sido devorados por el mercado (Figura 6).

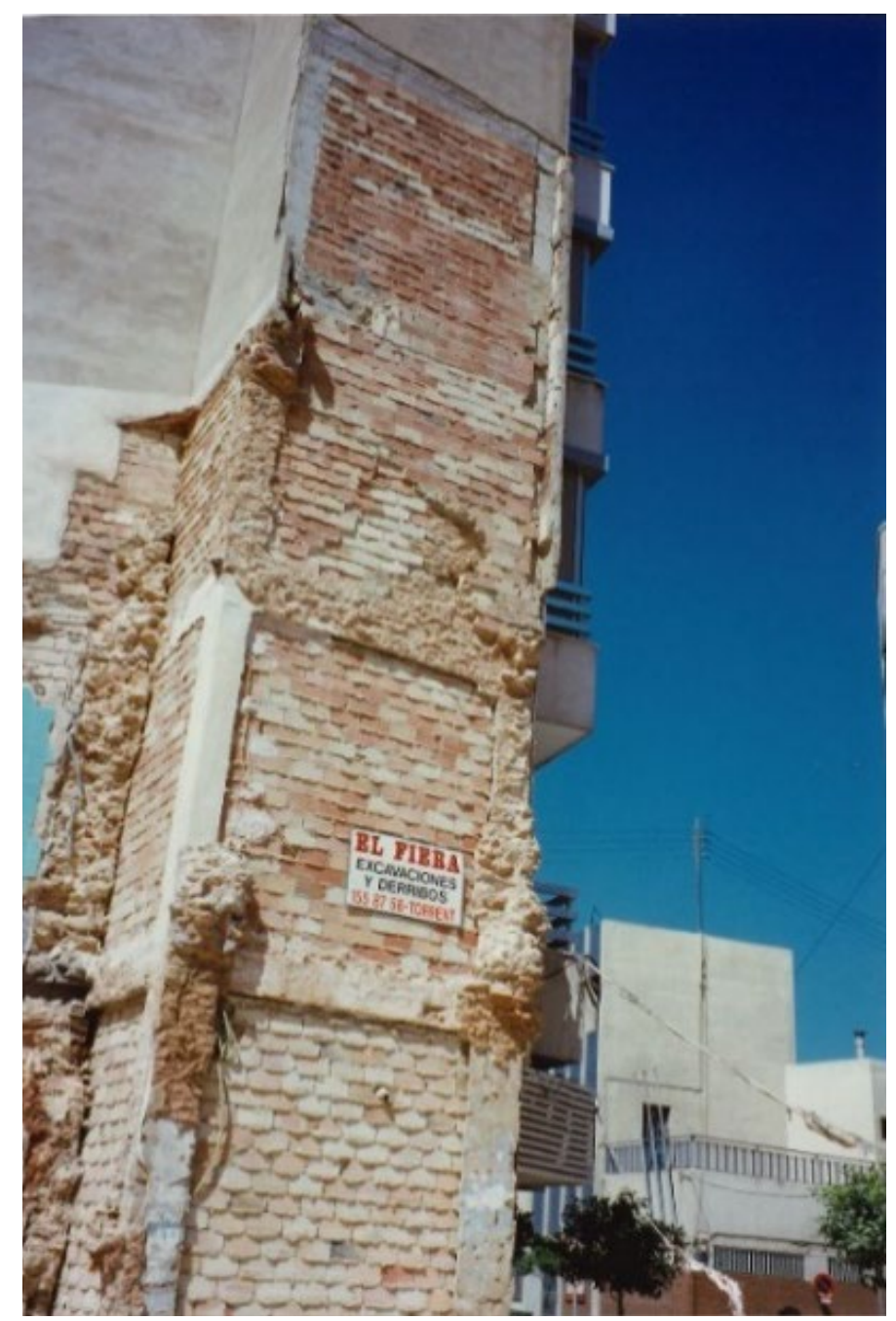

Figura 7. Empresa "El Fiera. Excavaciones y Derribos". 


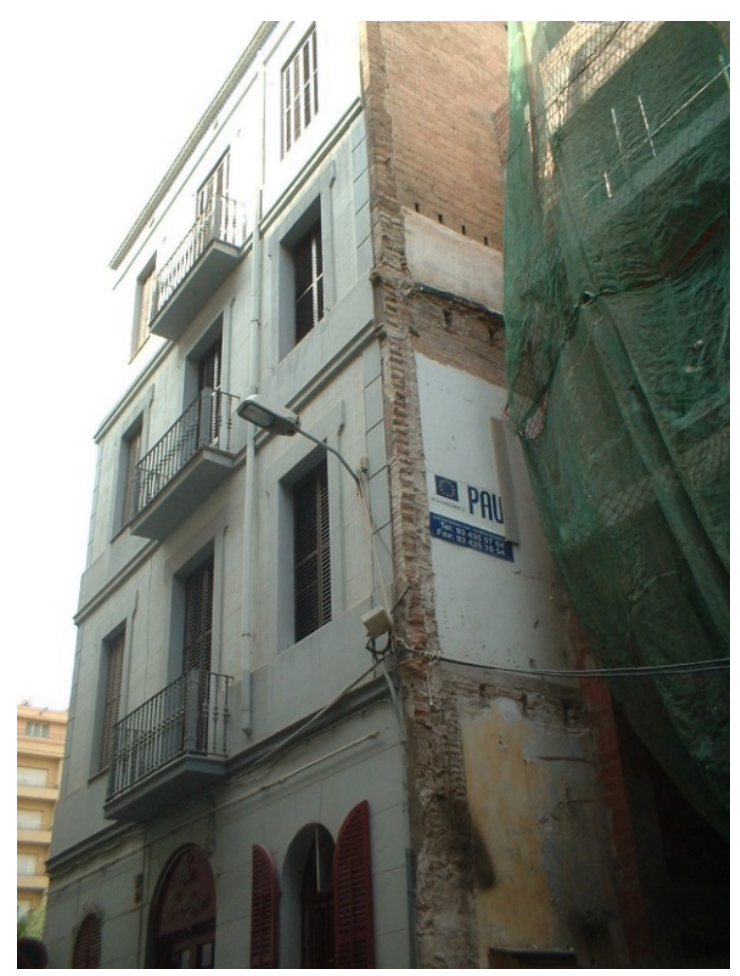

Figura 8. Empresa "Demoliciones Pau".

*El nombre de un producto.

Para los pueblos semíticos el nombre imprimía carácter en la persona que lo llevaba. Cuando queremos poner el nombre a algo, hay que buscar la esencia del producto.

- El "ensayo Barcelona"

Unos profesores de la UPC desarrollaron un ensayo de indentación que define la resistencia a tracción del hormigón de forma certera, y le pusieron al ensayo el nombre de "Ensayo Barcelona" (véase el ensayo y su resultado en las Figura 9 y Figura 10). Sin duda se venderá mejor en la comunidad científica acoplándose a esa marca que no deja de ser la ciudad donde nació y se desarrolló. He aquí un caso, elemental pero plenamente justificado de "nombre exacto y sugerente de las cosas".

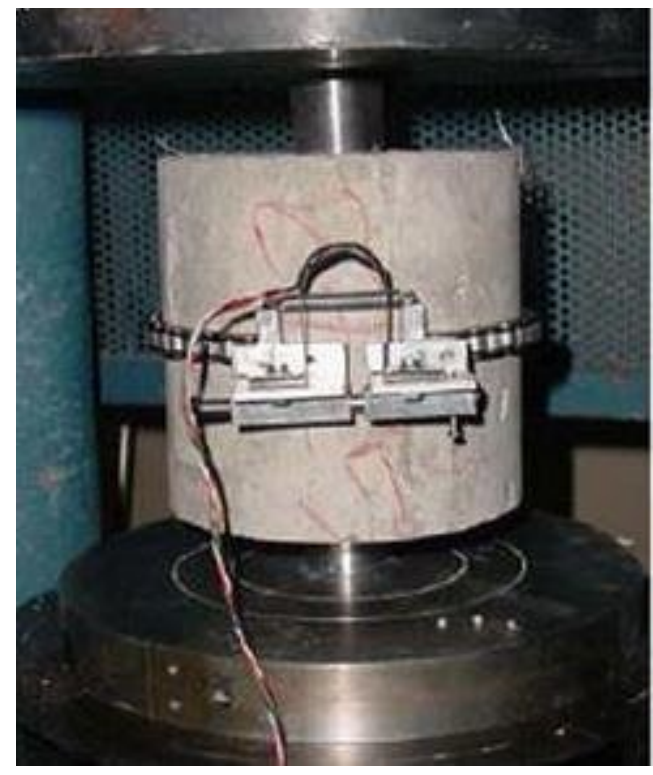

Figura 9. Ensayo Barcelona.

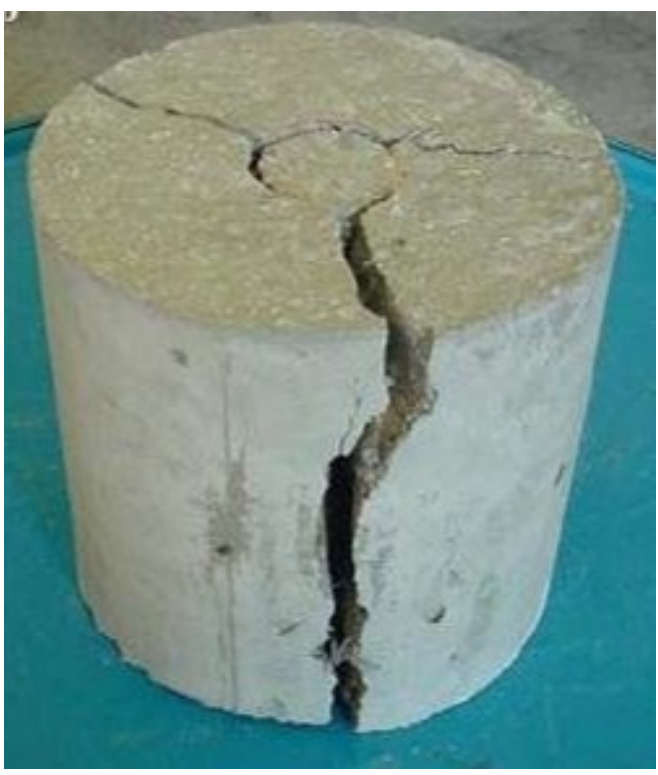

Figura 10. Ensayo de indentación. 


\section{- La ACE, "Asociación de Calculistas de Estructuras"}

En 1989 se creó en Cataluña la “Asociación de Calculistas de Estructuras” que, a principios de este siglo cambió su nombre por uno más preciso y, sobre todo, más digno: "Asociación de Consultores de Estructuras". Los arquitectos e ingenieros diseñan estructuras, son antes "estructuristas" que "calculistas". En la actualidad la ACE tiene más de 400 técnicos (ingenieros, arquitectos, aparejadores, ...) de prestigio, diseñando todo tipo de estructuras.

\section{*Frases que inducen a error}

Frases de algunos técnicos del oficio:

- "Esto siempre lo he hecho así". Muchas veces la traducción de esta frase, cuando conoces el tema, es "siempre lo hago mal".

- "Solución de gran coste de ejecución pero poco imaginativa". En un edificio religioso de los años 50, monolítico de mampostería y fábrica de ladrillo el estudio geotécnico muestra que hay 4 o $5 \mathrm{~m}$ de relleno que han provocado asientos generalizados en las paredes de mampostería y las bóvedas.

El arquitecto consultó con el ingeniero, el cual recomendó, de acuerdo con el estudio geotécnico, recalzar la estructura del edificio con micropilotes a 10 metros de profundidad. Es aquí donde el arquitecto esgrimió su frase: "Solución de gran coste de ejecución y poco imaginativa", ya que se le pedían soluciones alternativas que no encarecieran la intervención de la reparación. Después de una nueva consulta con su arquitecto "calculista" de confianza, se estudió la solución de cosido de grietas y refuerzo superpuesto a las zonas tensionadas de la estructura. Con el siguiente argumento también falaz: "Este tipo de intervención ha sido ejecutado con éxito en edificios que han sufrido fuertes tensiones estructurales con resultados satisfactorios y respetuosos con la geometría del edificio evitando intervenciones costosas y de gran duración en su ejecución”.

En conclusión, la solución técnica del ingeniero no solo no es poco imaginativa, sino que es la única solución que resuelve la causa del daño.

El arquitecto está obsesionado con el cálculo, al cual en este caso él no llega, así como con el coste; pero los ingenieros no calculan estructuras, las diseñan y resuelven en función de unos datos previos y de las condiciones de contorno.

El resultado final de ocultar el daño cosiendo grietas y pintando puede durar algún ciclo térmico si no se acrecientan los problemas del relleno, pero si se modifican las condiciones hidráulicas del terreno, habrá que recalzar haciendo caso al ingeniero, y probablemente volver a reparar las grietas "cosidas", con lo que el "gran coste de ejecución" aumentará posteriormente, contradiciendo también en esto las ideas del arquitecto.

\subsubsection{El lenguaje forense.}

El lenguaje forense es también dado al uso de técnicas y expresiones lingüísticamente singulares: * Jugar con el todo y las partes:

"El proyecto era incorrecto e incompleto" cuando lo que decía el documento de referencia era que "la información de la documentación previa para hacer el proyecto era incorrecta e incompleta". "Tomó decisiones arriesgadas" mientras el documento que analizaba decía que:

"la decisión del proyectista de fijar el trazado del nuevo túnel sin la completa seguridad de la situación final de un sifón era arriesgada". En singular, no en plural.

*Llamar "error" a algo que no lo es:

-Por ejemplo, el proyecto dice que, si la cota prevista para el tubo no es la correcta, se recalculará la bóveda al cambiar la rasante. Eso no es un "error de proyecto", es una previsión para cuando se pueda acceder a la información, que en este caso era una inversión económica importante que se definiría en obra. 
-Realizar una mejora a una solución justificada, y previamente aceptada de proyecto, tampoco es un error de proyecto, es una optimización a partir de los recursos de la obra.

*Utilizar el "silencio positivo"

Es un recurso para no cansar al lector, yendo al grano en los puntos importantes que pueden ofrecer dudas y disfunciones, y dando por supuesto que el resto de los temas no requieren ser tratados porque están bien (No news, good news).

* Recurrir al lenguaje gráfico

Con el lenguaje gráfico se puede inducir a errores, aunque el principal error es que se omitan dichos detalles gráficos. Véanse algunos ejemplos:

-Fotografiar de cerca una fisura, para impresionar o "dar miedo" tergiversando la realidad, cuando además no es algo relevante.

-Grafiar fisuras indiscriminadamente, sin explicar que no están a escala y que sirven para explicar la causa, y no simplemente pretenden asustar.

-Manipular la imagen, el "Photoshop".

\subsubsection{El lenguaje técnico del futuro.}

Cada construcción es un prototipo; no hay dos edificios iguales, dos puentes iguales, dos vigas iguales, ni dos probetas de hormigón iguales de la misma amasada; hasta el clima está sujeto a "un cambio climático" en nuestros días. Cada grieta puede ser objeto de una tesis doctoral, pero el técnico ha de simplificar el lenguaje. El trabajo lingüístico es ingente.

La palabra constituye también una fuente de errores de la que es difícil sustraerse. La comunicación es función del emisor y el receptor, y el lenguaje técnico ha de saber acercarse al social, al pericial, al periodístico y al político.

La medicina, que siempre va por delante en estos aspectos, nos ha enseñado en tiempos de pandemia la importancia de escuchar a la ciencia, para adoptar decisiones que hablen el mismo idioma. Cuando eso no ocurre, las ocurrencias políticas y sociales se disparan aleatoriamente porque el dinero lo puede todo y se crean desde negacionistas a triunfalistas, sin que se escuche la voz de los que saben, de los técnicos en la materia, aunque también sea limitada.

El lenguaje técnico ha de tratar de acercarse a los elementos, de incorporarse en ellos para "medir" su comportamiento en las variables que nos interesan, tratando de prevenir el riesgo de daño a través del estudio de la respuesta y de su evolución en el tiempo.

Hoy en día lo medimos todo, para comprender y ampliar el lenguaje técnico. Se puede colocar una red sin hilos de sensores microelectromecánicos embebidos en el hormigón que pueden detectar señales de luz, temperatura, vibraciones, etc... lo que llamamos "polvo inteligente" o "motas" para evaluar la variable que nos interesa en cada punto. Se puede colocar una fibra óptica en los puntos sensibles de un puente para conocer las microdeformaciones que se producen a lo largo de toda su vida útil, se pueden colocar acelerómetros para estudiar las variaciones de rigidez. En definitiva, con la medición y el estudio de los parámetros fundamentales, se pueden establecer planes de contingencia que indiquen la necesidad de avisos, alertas o alarmas durante su vida útil y con ello permitan valorar el riesgo y la vulnerabilidad de esa infraestructura.

La tecnología ha supuesto una cultura para controlar el miedo, pero como se decía al principio el riesgo cero no existe y el "miedo cero" tampoco.

La influencia de las nuevas tecnologías se aprecia por ejemplo en Stephen Pincker, que considera el lenguaje como una categoría digital, un sistema digital de comunicación. Nuestro cerebro, que también es digital (proposicional, lógico) tiene aspectos analógicos (instintivos) como la intuición, la percepción.

En el futuro estaremos pasando de las ecuaciones diferenciales a los algoritmos, de lo analógico a lo digital, en resumen, del lenguaje técnico al lenguaje poético que las estructuras y sus subsistemas nos enseñan. 


\section{CONCLUSIONES}

Hemos de avanzar hacia la poesía del lenguaje técnico, no en vano, las vigas de las estructuras tienen "alma" y "alas", y los forjados "vuelan" algún metro.

Se han puesto ejemplos del uso actual del lenguaje y sus consecuencias, tratando de incidir a través de casos prácticos en la necesidad de su mejora continua. Después de ensalzar los valores de la palabra, conviene resaltar que la obligación de un patólogo es también promocionar el silencio, ya que su obligación al realizar una primera visita técnica es ver, oír y callar, para entre otras cosas, no alentar la alarma social con opiniones improvisadas, que distan siempre de una respuesta técnica. El tema no es fácil; poco después de la caída de las torres gemelas ya había informes explicándola, pero el FEMA (Federal Emergency Management Agency) tardó casi un año (mayo 2002) en realizar el estudio de las causas, cubriendo como debe ser todas las etapas de un estudio de daños: recopilar información, hacer una exhaustiva toma de datos, ensayos, análisis estructural y de los daños, y conclusiones. En este caso, donde parecía lógico escuchar a los técnicos con información, unos de los primeros en llamar al ingeniero responsable de la construcción, Less Robertson, fueron como él mismo nos cuenta (10) los abogados del arquitecto, amenazando por si había que delimitar responsabilidades. El lenguaje forense nos invade.

Un último ejemplo de la transversalidad del lenguaje es lo que podríamos denominar como el "síndrome del padre afectado". Cuando un padre va a ver los daños en un edificio escolar, no preguntará si el coeficiente de mayoración de acciones de la estructura dañada es mayor que la unidad. La transversalidad y la poesía llevarán a un lenguaje "equivalente". Muy probablemente pedirá un "riesgo cero" que nadie le podrá dar. Siendo así y vistos los daños, si tuviera que llevar a su hijo al colegio, ¿lo llevaría?

\section{AGRADECIMIENTOS}

A todos aquellos que día a día contribuyen a acercarnos a través del lenguaje de la amistad. A mi hermano Alfonso Alegre Heitzmann, poeta, coautor de este escrito, al que no puede adherirse por falta de rigor lingüístico y poesía.

\section{REFERENCIAS}

(1) J.M. Bover F. Cantera. “Evangelio según San Juan”. 1947.

(2) Álvaro García Meseguer. "La patología y el lenguaje. Informes de patología”. Informes de construcción Vol. 37 nº 376. 1985.

(3) Atkinson, A.R. "Human error in the management of building projects". Construction Management Economics, Vol. 16., pp 339-49. 1998.

(4) Shoet y Frydman. "Communication Patterns in Construction at Construction Manager Level”. Journal of Construction Engineering and Management 129(5). 2003.

(5) Juan Ramón Jiménez. “Eternidades”.1918.

(6) Sabatino Moscati. "Las antiguas civilizaciones semíticas”. Ediciones Garriga. Barcelona. 1960.

(7) Ovidio. "Metamorfosis”, traducción y notas de Ely Leonetti Jungl. Colección Austral. Madrid. 2005.

(8) “Libros de Apeos del Ayuntamiento de Ohanes”. Archivo Municipal. 1939.

(9) Antonino Colino. "Revista de Obras Públicas 3626”. Ene/Feb 2021.

(10) Leslie E. Robertson. “The structure of design”. The Monacelli Press Singapore. 2017. 